Article

\title{
Functional Area Recognition and Use-Intensity Analysis Based on Multi-Source Data: A Case Study of Jinan, China
}

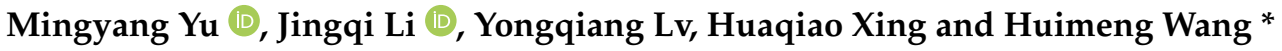 \\ College of Surveying and Geo-Informatics, Shandong Jianzhu University, Jinan 250101, China; \\ ymy@sdjzu.edu.cn (M.Y.); 2019165116@stu.sdjzu.edu.cn (J.L.); lvyongqiang19@sdjzu.edu.cn (Y.L.); \\ xinghuaqiao18@sdjzu.edu.cn (H.X.) \\ * Correspondence: wanghuimeng20@sdjzu.edu.cn
}

Citation: Yu, M.; Li, J.; Lv, Y.; Xing, H.; Wang, H. Functional Area Recognition and Use-Intensity Analysis Based on Multi-Source Data: A Case Study of Jinan, China. ISPRS Int. J. Geo-Inf. 2021, 10, 640. https:// doi.org/10.3390/ijgi10100640

Academic Editors: Yeran Sun and Wolfgang Kainz

Received: 30 June 2021

Accepted: 20 September 2021

Published: 24 September 2021

Publisher's Note: MDPI stays neutral with regard to jurisdictional claims in published maps and institutional affiliations.

Copyright: (c) 2021 by the authors. Licensee MDPI, Basel, Switzerland. This article is an open access article distributed under the terms and conditions of the Creative Commons Attribution (CC BY) license (https:// creativecommons.org/licenses/by/ $4.0 /)$.
Abstract: This paper proposes a GIS-based field model for hot-spot extraction based on POI data and analyzes the use intensity of functional areas by using Tencent location data to identify and describe the morphological characteristics and dynamic use intensity of facilities in urban functional areas. Taking the four districts of Jinan City Center as an example, we used the generalized symmetric structure spectrum and digital field-based hierarchical geo-information Tupu to extract facility hot spots. Tencent location data were then applied to quantify differences in the use intensity of functional areas between workday and weekend, as well as between daytime and nighttime. Finally, refined research on functional areas was realized from a dynamic point of view. Results showed that (1) the generalized symmetric structure spectrum and digital field-based hierarchical geo-information Tupu can identify and express the characteristics of the spatial distribution and hierarchical structures of urban facility hot spots at the horizontal and vertical levels, respectively; (2) overall, the distribution of all types of functional areas presents the characteristics of "circular structures," which form a spatial pattern of "multi-center" groups and "single/mixed" functional areas; (3) aside from residential facilities, green space and square land facilities have the highest use intensity; this finding highlights the tourism characteristics of Jinan. Low-use intensity areas are distributed at the periphery of the four districts, while high-use intensity areas, the functional type of which is mainly business facilities, are mainly distributed around the urban area. These results are helpful to the development strategy of the city's efforts to adapt to economic change and provide a scientific basis for the functional orientation of Jinan City.

Keywords: POI; Tencent location data; generalized symmetric structure spectrum; digital field-based hierarchical geo-information Tupu; use intensity of a functional area

\section{Introduction}

As a geographic product, a city is characterized by various social activities and material resources. Continuous developments encourage cities to undergo changes in their structure and function; these changes gradually form different functional regions, including commercial, residential, and industrial regions [1]. The accurate and timely identification and analysis of urban functional areas and structures are essential to measure the status of urban development and support the planning and management of cities accurately. The traditional method for identifying and dividing urban functional areas involves field research, which requires considerable human and material resources and time. Moreover, the reliability and comprehensiveness of the data obtained cannot meet requirements and are easily influenced by human factors [2]. These issues render the accurate quantification or reasonable identification of the nature of urban land use and functional areas, especially the dynamic use of urban functional areas, quite challenging.

Many scholars in China and elsewhere have used multi-source data to explore the spatial distributions of cities and delineate the boundaries of functional areas. For example, 
using crowd-sourced data, Crooks et al. [3] analyzed urban spatial function information to capture the evolving nature of urban form and function. Wu et al. [4] used taxi data to count the number of ODs in various plots at different periods and proposed different functional area index factors and calculation methods based on OD characteristics; the authors also conducted a functional area identification analysis of their study area. Shan et al. [5,6] used kernel density analysis and the local Getis-OrdGi* index method in combination with a geographically weighted regression and spatial measurement model to explore the distribution patterns of urban facilities on the basis of geographic big data. Xue et al. [7] introduced the current economic structures of various cities in detail and discussed the spatial characteristics of these cities from an industrial perspective by using POI data. Gao et al. [8] developed a statistical framework to help discover semantically meaningful topics and functional regions based on the co-occurrence patterns of POI types; this strategy realized the supplement of social perception view of urban space based on human activities. Using crawling POI data, Gil et al. [9] identified trends in the distribution of POIs in three urban centers in Seoul and explored the attractiveness of different tourist destinations to visitors.

The above research focuses on the identification and analysis of the overall functional structure of cities. The factors driving individual industries or special regions in cities have also become a research focus for many scholars. For example, Yao et al. [10] used 20 million gourmet consumption data records collected from 31 provincial capitals in mainland China to calculate the sugar consumption in urban areas, understand the spatial distribution of sugar consumption in the modern Chinese diet, and identify the related factors. Gao et al. [11] used kernel density estimation and buffer analysis to characterize the spatial agglomeration state and regional focus of the retail industry in Xi'an. Here, the spatial clustering relationships among retail industries were explored by using bivariate spatial autocorrelation and nearest-neighbor analysis. Using spatial point-level data for nine types of urban public service facilities in Beijing, Zhan et al. [12] employed the cumulative opportunity method to measure the accessibility of urban public service facilities in Beijing and then further analyzed the mixed functions and influencing factors of urban public service facilities. María Henar Salas-Olmedo et al. [13] extracted the digital footprint of tourists in Madrid, Spain, by using cluster and spatial autocorrelation analyses based on three data sources - namely, Panoramio, Foursquare, and Twitter; the group then compared the results of these three data sources to analyze their individual accuracy.

The above studies generally discuss the spatial structures and driving factors of a given city as a whole or explore facility elements individually. However, the identification and analysis of urban functional areas from multiple angles remain necessary to explore the dynamic use of urban functional areas at a finer scale.

Big data are widely used in various industries and fields to promote the progress and development of society. Some examples of big data include Weibo check-in data, Tencent location data, and point of interest (POI) data. POI data record the spatial and attribute information of geographical entities, including their names, categories, addresses, and coordinates. Using POI data, we can reliably identify the type of urban land and analyze the functional structures of a city [14]. Tencent location data are based on Tencent's global coverage and high-precision positioning data, which feature the advantages of a large number of users, high spatial-temporal resolution, and close association with daily life. Thus, big data are widely used in studies of inter-city population flows, urban spatial connection modes, and population distributions $[15,16]$.

The present paper proposes a GIS-based field model for hot-spot extraction based on POI data and then analyzes the use intensity of functional areas by using Tencent location data [17]. Taking the city of Jinan as an example, we first used the frequency density (FD) method to identify different functional areas [18,19]. Then, we comprehensively verified the rationality and accuracy of the identification of functional areas by using remote sensing images and a map of Jinan. We introduced a GIS-based field model for hot-spot extraction and constructed a generalized symmetric structure spectrum and digital field hierarchical 
geo-information Tupu to explore the spatial patterns and agglomeration conditions of the four central districts of Jinan at the horizontal and vertical levels [20-24]. Finally, Tencent location data were used to quantify differences in the use intensity of functional areas between workday and weekend, as well as between daytime and nighttime. Our work reveals the composition and characteristics of urban functional areas from different dimensions, such as time and space. This research contributes to the understanding of the spatial distribution patterns of various functional facilities in Jinan by developing a research model of future urban development via a systematic study of urban functional areas and the use intensity of these areas.

\section{Materials and Methods}

\subsection{Study Area}

A city's urban center forms the core of its public activity system. A typical urban center is characterized by a well-developed infrastructure and a high concentration of political, cultural, and economic industries that can fully demonstrate the city's status and level of economic development. As the capital of Shandong Province, Jinan is the central city of the Shandong metropolitan area; it is a typical piedmont plain city featuring plains, mountains, and hills, with a complex topography and relatively complete urban functions considering its natural, human-related, and economic conditions. In this study, four districts in central Jinan - namely, Shizhong District, Lixia District, Huaiyin District, and Tianqiao District, covering a total area of $781.37 \mathrm{~km}^{2}$, were selected as the study area (Figure 1).

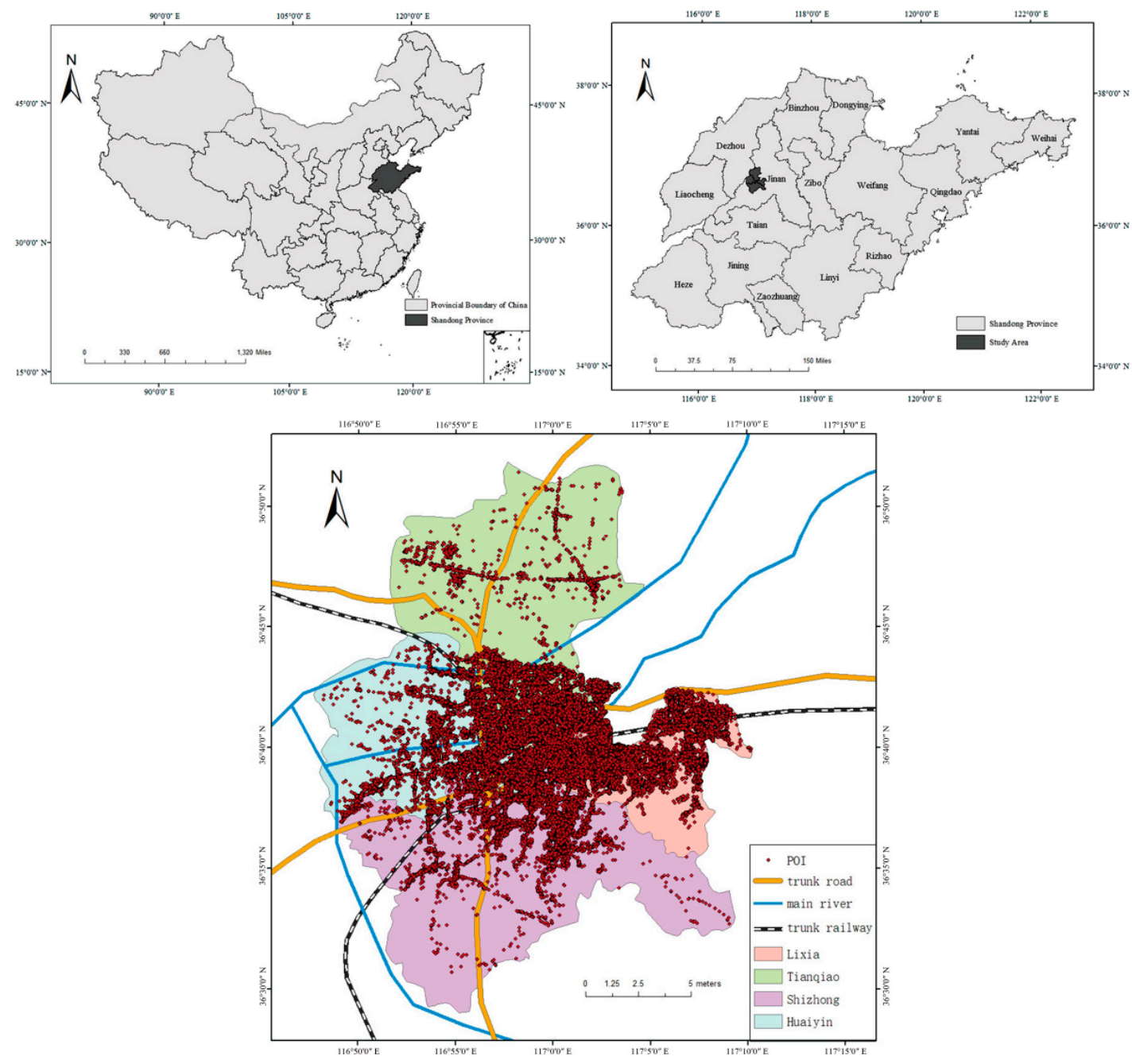

Figure 1. Schematic representation of the study area. 


\subsection{Data}

\subsubsection{POI Data}

The POI data used in this study were obtained from the AutoNavi Maps Open Platform (https:/ / lbs.amap.com/, accessed on 15 April 2019). Each POI record includes the name, longitude, latitude, zoning, and geographic entity of a specific location. The POI data were cleansed and spatially adjusted to obtain the POI data of 48,681 areas recorded in 2019. To improve the reliability of our results, we divided the POI data into six categories according to the Urban Land Use Classification and Planning and Construction Land Use Standards as follows: residential land, public management and service facilities land, business facilities land, industrial land, road and transport facilities land, and green space and square land [25-27]. The largest number of sites belonged to the business facility category, which accounted for $47.3 \%$ of the data, followed by the public management and service facility category, which accounted for $18.5 \%$ of the data. The smallest number of sites belonged to the green space and square land category, which accounted for only $2.1 \%$ of the data (Table 1). The attribute information of each category of POI data was then more finely divided; for instance, business facilities were divided into hotels, restaurants, shopping centers, financial services, living services, automobile services, and other subcategories after comprehensive analysis and research (Table 1).

Table 1. POI data classification.

\begin{tabular}{cccc}
\hline Functional Area Category & POI Data Classification & Quantity & Percentage \\
\hline Residential land & Real estate & 3362 & $7.00 \%$ \\
Public management and service & Scientific and educational cultural, Leisure and & 8929 & $18.50 \%$ \\
facilities land & entertainment, Government agencies & & $47.30 \%$ \\
Business facilities land & Accommodation, Catering, Shopping, Finance, Life & 22,771 & $11.10 \%$ \\
Industrial land & services, Automobile services & 5316 & $14.00 \%$ \\
Roads and transport facilities land & Company, Enterprise & 6748 & $2.10 \%$ \\
Green spaces and squares land & Road, Transportation facilities & 1022 & Park Plaza, Scenic spot \\
\hline
\end{tabular}

Relying only on the distribution of POI data to identify urban area functions is insufficient because urban functional areas are closely related to public perceptions, individual characteristics, and the footprint of POI data points. Therefore, we adopted a multifactor weighting method to evaluate and assign values to POI points [28]. Using remote sensing images and online data queries, we roughly determined the average building area or floor space of various POIs. We also referred to Zhao Weifeng's rank order of public awareness. The corresponding weights assigned to various POI points are shown in Table $2[29,30]$.

Table 2. Data weights for each type of POI.

\begin{tabular}{cccccccc}
\hline Category & Weight & Category & Weight & Category & Weight & Category & Weight \\
\hline $\begin{array}{c}\text { Real estate } \\
\begin{array}{c}\text { Scientific and } \\
\text { educational culture }\end{array}\end{array}$ & 0.6706 & Accommodation & 0.5562 & Living services & 0.5010 & road & 1 \\
$\begin{array}{c}\text { Leisure and } \\
\text { entertainment }\end{array}$ & 0.5010 & Chopping & 0.8146 & Medical care & 0.5069 & park plaza & 0.6548 \\
Government agency & 0.3550 & Finance & 0.3057 & Company enterprise & 0.3057 & scenic area & 0.8245 \\
\hline
\end{tabular}

\subsubsection{Tencent Location Data}

The Tencent location data used in this research were collected from https:/ / heat.qq. com and accessed on 27 March 2019 [15,16]. We collected Tencent location data for Jinan on 27 and 30 March 2019. The research period was divided into workdays and weekends, as well as daytime and nighttime. Daytime hours ranged from 7:00 to 18:00, while nighttime 
hours ranged from 19:00 to 6:00. The dataset had an hourly temporal resolution and a $1 \mathrm{~km} \times 1 \mathrm{~km}$ spatial resolution.

\subsubsection{Other Data}

In this paper, in addition to POI and Tencent location data, we also used administrative division data, Jinan City road network data, and remote sensing images. The remote sensing images used in this paper were obtained from USGS National Map Viewer (http:/ / viewer.nationalmap.gov/viewer/, accessed on 15 April 2019). The urban road network and administrative division data of Jinan were obtained from the Open Street Map (OSM) geographic data platform (https: / / www.openstreetmap.org/, accessed on 18 April 2019). OpenStreetMap ${ }^{\circledR}$ is an open data source licensed under the Open Data Commons Open Database License by the OpenStreetMap Foundation (https: / www.openstreetmap. org/copyright/, accessed on 18 April 2019); OSM data use is also governed by the CC BY 4.0 license (https: / / creativecommons.org/licenses/by/4.0/, accessed on 25 April 2019). Some of the many advantages of OSM data include high richness, real-time updates, and fast update speeds, which is the most popular spontaneous geographic information at this stage.

\subsection{Research Framework}

This paper includes three main parts: functional area recognition analysis, hot-spot detection analysis, and functional area use intensity analysis. We used the POI data for functional area recognition analysis to identify the spatial location distribution of facilities in the research area. Hot-spot detection analysis was then conducted using a regional hot-spot detection method, generalized symmetric structure spectrum, and digital fieldbased hierarchical geo-information Tupu to explore the spatial distribution characteristics of six types of facilities in the research area; the laws and mechanisms of the geographic distribution of these facilities were also explored. Finally, Tencent location data were used to quantify differences in the use intensity of functional areas between workday and weekend and between daytime and nighttime. This work reveals the composition and characteristics of urban functional areas from different dimensions, such as time and space. The complete research framework of this study is shown in Figure 2.

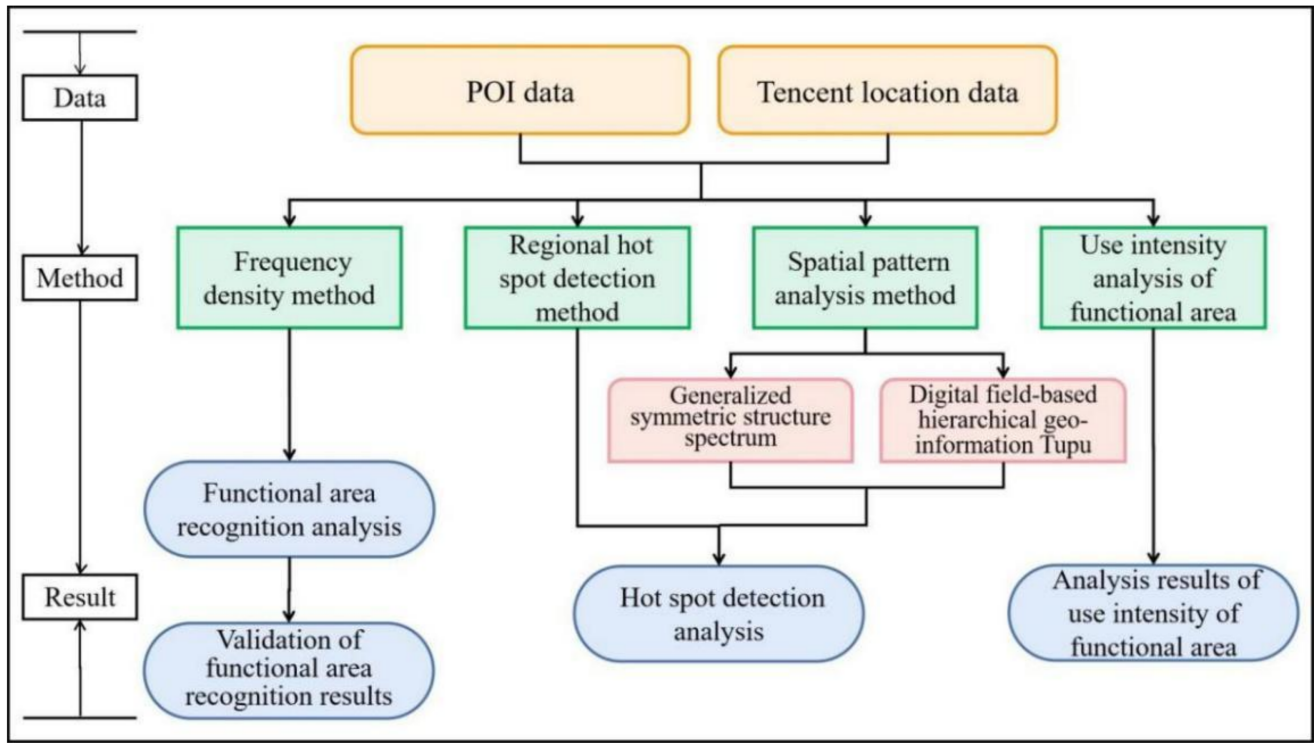

Figure 2. Research framework (analysis data, method, and result). 


\subsection{Methods}

\subsubsection{Frequency Density Method}

We performed POI data reclassification and then applied a $400 \mathrm{~m}$ grid as a basic unit after repeated experiments [31]. The POI data were then superimposed on the fishnet data of the four central districts, FD was used to calculate the ratio of each type of POI within the unit to the total number of POIs in the category, and the category ratio was constructed to identify urban functional areas. The related calculation formulas are as follows:

$$
\begin{gathered}
F_{I}=\frac{n_{i}}{N_{i}},(i=1,2, \ldots, 6) \\
C_{i}=\frac{F_{i}}{\sum_{i=1}^{6} F_{i}},(i=1,2, \ldots, 6)
\end{gathered}
$$

where $i$ is the type of POI, $n_{i}$ is the number of units in the POI category $i, N_{i}$ is the first category of the respective POI, $F_{i}$ is the first category of the POI accounting for the total number of POI categories, which is used to calculate the FD, and $C_{i}$ is the first category of the POI FD that proportionally accounts for the FDs of all POIs.

A $50 \%$ ratio of the selected type was used as the criterion to determine single- versus mixed-function areas. In a given unit, when the proportion of a certain type of POI exceeded $50 \%$, the functional properties of the unit were considered to be determined by that POI. When the proportions of all types of POIs in a given unit were over 0 but less than $50 \%$, the area was considered a mixed-function area, and the types of this unit were determined by the top three most represented POIs. Finally, when the proportion of all types of POIs in a unit was 0 , the area was considered to not have various facilities, and no area data were available [32].

\subsubsection{Regional Hot-Spot Detection Method}

We can construct a density field surface model to show the spatial density distribution characteristics of the POI data as a whole by using the kernel density analysis method. However, we cannot accurately express the specific region or peak of a hot spot. Thus, we used a GIS-based field model for hot-spot extraction to detect the location of the maximum value in a given local region and then applied window detection to obtain the raw heat surface values of all hot spots; this model can quantitatively describe hot spots and analyze the overall distribution pattern of these spots. Moreover, the clustering algorithm was used to classify hot spots, and the hot-spot rankings at all levels in the entire research area were obtained. A probability density surface was constructed for each type of facility by using the Gaussian kernel function. The calculation formula of the specific principle is as follows:

$$
f(x, y)=\frac{3}{n \pi r^{2}} \sum_{i=1}^{n} E\left[1-\frac{\left(x-x_{i}\right)^{2}+\left(y-y_{i}\right)^{2}}{r^{2}}\right]^{2}
$$

where $f(x, y)$ represents the hot-spot density of the calculation unit, $n$ represents the number of sampling points within the bandwidth, $r$ represents the bandwidth, $E$ represents the kernel function, $x$ and $y$ are the coordinates of the calculation unit, and $x_{i}$ and $y_{i}$ are the coordinates of the sampling points.

Using the above formula to calculate the probability density matrix $A$ with $\mathrm{m}$ rows and $n$ columns yields the following expression:

$$
A=\left(a_{i j}\right)_{m n}=\left[\begin{array}{cccc}
a_{11} & a_{12} & \cdots & a_{1 n} \\
a_{21} & a_{22} & \cdots & a_{2 n} \\
\cdots & \cdots & \cdots & \cdots \\
a_{m 1} & a_{m 2} & \cdots & a_{m n}
\end{array}\right](i=1,2, \ldots, m ; j=1,2, \ldots, n .)
$$


For any element $a_{i j}$ in matrix $\mathrm{A}$, we can find the eight adjacent neighborhood elements that form a subset $W_{i j}$ of matrix $\mathrm{A}$ and satisfy $W_{i j} \in A$. Thereafter, we calculated the maximum value in matrix $W_{i j}$. We then took the maximum value of all elements in $W_{i j}$ and obtained a new matrix subset $W_{i j m a x}$. The use of step matrix $A$ to perform calculations yields the new matrix $B$. The following example is used to illustrate the calculation steps for ease of understanding. The sample matrix is as follows:

$$
A^{\prime}=\left(a_{i j}\right)_{44}=\left[\begin{array}{llll}
a_{11} & a_{12} & a_{13} & a_{14} \\
a_{21} & a_{22} & a_{23} & a_{24} \\
a_{31} & a_{32} & a_{33} & a_{34} \\
\boldsymbol{a}_{41} & a_{42} & \boldsymbol{a}_{43} & a_{44}
\end{array}\right]\left(\boldsymbol{a}_{14}>\boldsymbol{a}_{22}>\boldsymbol{a}_{41}>\boldsymbol{a}_{43}\right)
$$

In the formula, the boldfaced element is the local maximum.

$$
W_{11}=\left[\begin{array}{ccc}
0 & 0 & 0 \\
0 & a_{11} & a_{12} \\
0 & a_{21} & a_{22}
\end{array}\right]
$$

As $a_{11}$ is at the edge of the matrix, some adjacent elements do not exist; thus, these elements can be set to 0 . A new matrix $W_{i j m a x}$ that meets the above requirements is then obtained.

$$
W_{11 \text { max }}=\left[\begin{array}{ccc}
0 & 0 & 0 \\
0 & \boldsymbol{a}_{22} & \boldsymbol{a}_{22} \\
0 & \boldsymbol{a}_{22} & \boldsymbol{a}_{22}
\end{array}\right]
$$

Similarly,

$$
W_{12 \max }=\left[\begin{array}{ccc}
0 & 0 & 0 \\
\boldsymbol{a}_{22} & \boldsymbol{a}_{22} & \boldsymbol{a}_{22} \\
\boldsymbol{a}_{22} & \boldsymbol{a}_{22} & \boldsymbol{a}_{22}
\end{array}\right], W_{13 \max }=\left[\begin{array}{ccc}
0 & 0 & 0 \\
\boldsymbol{a}_{14} & \boldsymbol{a}_{14} & \boldsymbol{a}_{14} \\
\boldsymbol{a}_{14} & \boldsymbol{a}_{14} & \boldsymbol{a}_{14}
\end{array}\right], W_{14 \max }=\left[\begin{array}{ccc}
0 & 0 & 0 \\
\boldsymbol{a}_{14} & \boldsymbol{a}_{14} & 0 \\
\boldsymbol{a}_{14} & \boldsymbol{a}_{14} & 0
\end{array}\right]
$$

For elements without edge effects, such as $a_{23}$, due to

$$
a_{23}=\left[\begin{array}{lll}
a_{12} & a_{13} & a_{14} \\
a_{22} & a_{23} & a_{24} \\
a_{31} & a_{32} & a_{34}
\end{array}\right]\left(a_{14}>a_{22}\right)
$$

Therefore, the calculation result of $W_{23 \max }$ is:

$$
W_{23 \max }=\left[\begin{array}{lll}
a_{14} & a_{14} & a_{14} \\
a_{14} & a_{14} & a_{14} \\
a_{14} & a_{14} & a_{14}
\end{array}\right]
$$

When all elements are calculated, the local maximum matrix $B^{\prime}$ of the entire sample matrix $A^{\prime}$ is calculated as follows:

$$
B^{\prime}=\left[\begin{array}{llll}
a_{22} & a_{22} & a_{14} & a_{14} \\
a_{22} & a_{22} & a_{22} & a_{43} \\
a_{41} & a_{41} & a_{22} & a_{43} \\
a_{41} & a_{41} & a_{43} & a_{43}
\end{array}\right]
$$

Finally, we calculate the difference between the local maximum matrix $B^{\prime}$ and the probability density matrix $A^{\prime}$ and reassign each element as follows: when $a_{i j}<0, a_{i j}=0$; when $a_{i j} \geq 0, a_{i j}=1$. This step yields a new matrix $C^{\prime}$. 


$$
C^{\prime}=B^{\prime}-A^{\prime}=\left[\begin{array}{llll}
0 & 0 & 0 & 1 \\
0 & 1 & 0 & 0 \\
0 & 0 & 0 & 0 \\
1 & 0 & 1 & 0
\end{array}\right]
$$

In matrix $C^{\prime}$, the element with value 1 is located in a hot-spot area. Multiplying $C^{\prime}$ with prime numbers leads to matrix $R^{\prime}$ with hot-spot values.

$$
R^{\prime}=A^{\prime} C^{\prime}=A^{\prime}\left(B^{\prime}-A^{\prime}\right)=\left[\begin{array}{cccc}
0 & a_{12} & 0 & \boldsymbol{a}_{14} \\
0 & \boldsymbol{a}_{22} & 0 & 0 \\
0 & 0 & 0 & 0 \\
\boldsymbol{a}_{41} & 0 & \boldsymbol{a}_{43} & 0
\end{array}\right]
$$

The hot-spot detection method based on various functional facilities is as shown above. The result was obtained by detecting the hot spots of various facilities and classifying them into different levels via the natural break clustering method.

The process of hot-spot extraction using the GIS-based field model is shown in Figure 3.

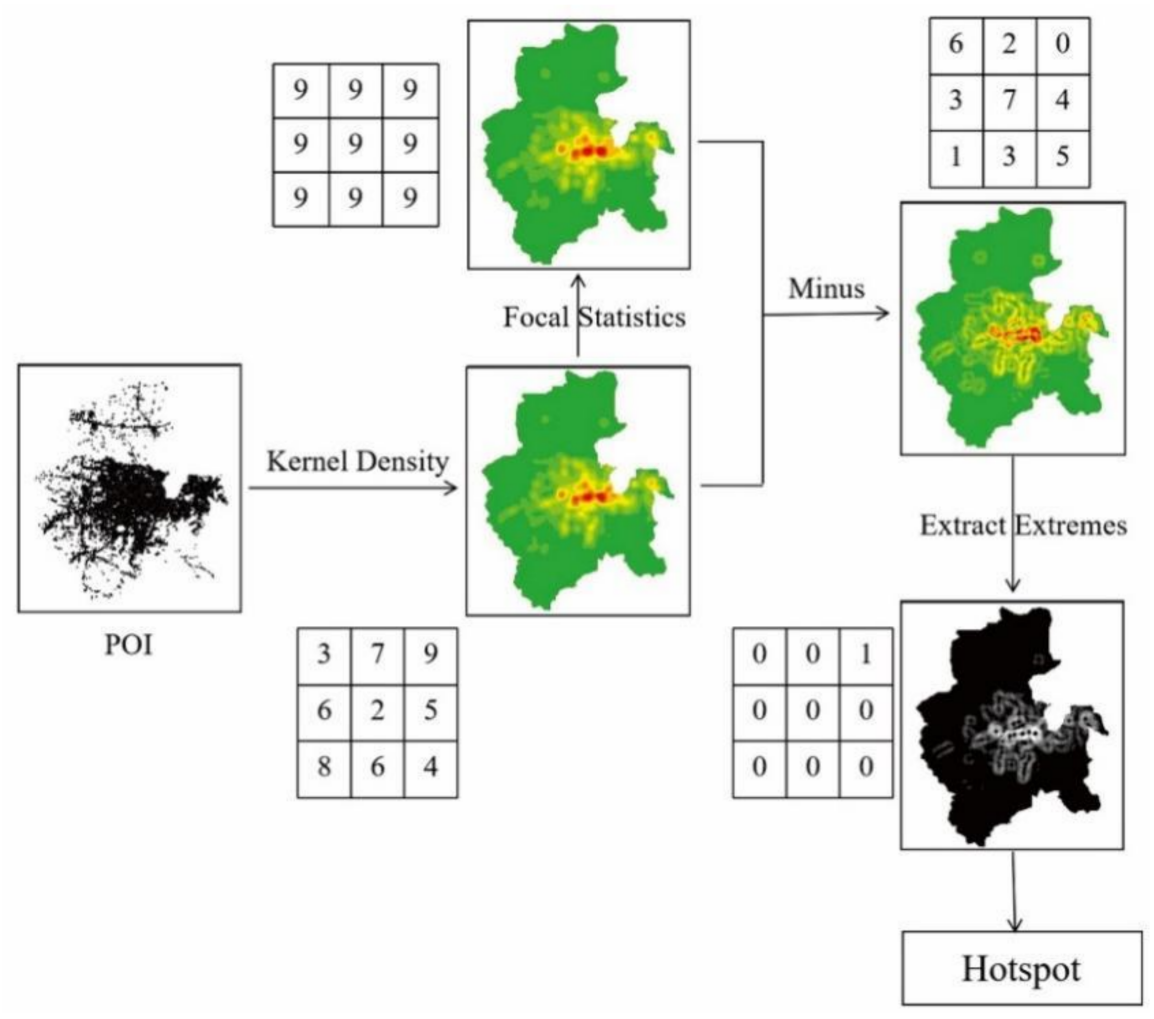

Figure 3. Regional hot-spot detection.

\subsubsection{Spatial Pattern Analysis Method}

Geo-information TuPu is a new research direction proposed by Shupeng Chen [33] that could be used to digitize and serialize graphic images to reveal the spatial structure of objects and phenomena. This technology can express the essential attributes of complex issues concisely and intuitively, and deepen the elucidation and multi-dimensional expression of the internal laws of various processes and changes. It can study the urban form and structure from multiple perspectives, qualitative and quantitative, and deeply tap into the potential deep-seated information. The geo-information map method is a change in our way of thinking about the study of urban form and structure with many different forms of expression, among which the generalized symmetric structure spectrum and 
digital field-based hierarchical geo-information Tupu are the most widely used. This article used the generalized symmetric structure spectrum to analyze the spatial differentiation structure characteristics of the six types of functional facilities and then applied the digital field-based hierarchical geo-information Tupu to analyze the spatial hierarchical structural characteristics of these six facilities. These two geographic structure maps can reveal urban functions, the distribution law of the space structure of facilities, and the level and scale of the spatial structure of urban functional facilities.

The generalized symmetric structure spectrum is mainly based on the traditional geometric symmetry perspective and fully applies the founding conditions of symmetric features in the spatial structure symmetry of geographical objects. This approach could help researchers describe the characteristics of urban spatial structures and analyze symmetric information between spatial objects. A coupling relationship between the symmetric structure and spatial distribution of geographical objects may be observed. The use of a generalized symmetrical structure to analyze spatial features can explain the distribution laws and structural hierarchical scales of spatial structures within a city, as well as extract the spatial distribution structures of hot spots horizontally. The eight main generalized symmetric structure spectra are shown in Figure 4. These symmetrical structures can reveal the laws and mechanisms of geographic development in an urban space. For example, the antisymmetry observed in Figure 4e can explain the siphon phenomenon in urban development, that is, large cities with the strongest economic strength and the greatest development potential can attract the resources of the surrounding small and medium cities and some small towns. The development of Shenzhen in China is a manifestation of the antisymmetric structure. Shenzhen's strong attraction attracts talents from small cities along the route, thereby hindering the development of these areas. The curvilinear symmetry shown in Figure $4 \mathrm{~g}$ can be used to describe the distribution trend of cities along rivers and highways.

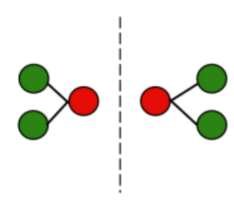

(a) Axial symmetry

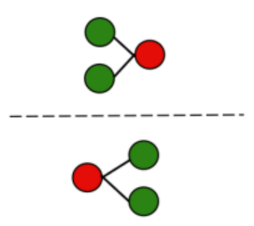

(e) Antisymmetry

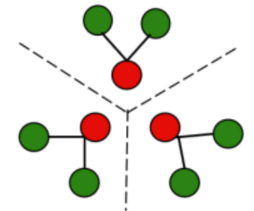

(b) Rotational symmetry

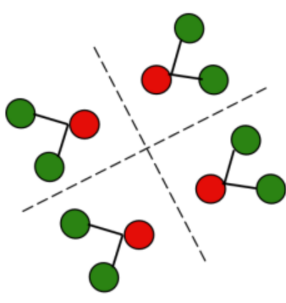

(f) Oblique symmetry

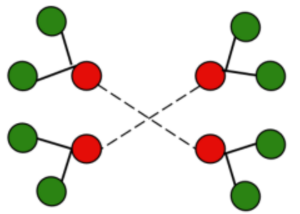

(c) Centrosymmetry

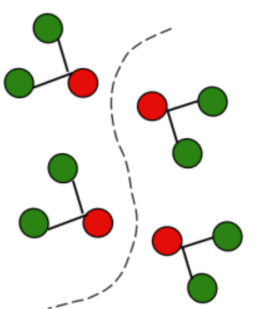

(g) Curvilinear symmetry

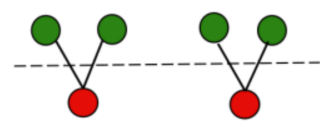

(d) Translational symmetry

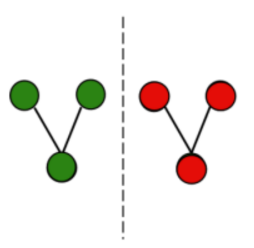

(h) Color symmetry

Figure 4. Generalized symmetric structure spectrum (GSSC).

The digital field-based hierarchical geo-information Tupu includes the isodensity digital atlas and the isodensity hierarchical tree, which can quantitatively express the scale and hierarchical structure of the hot spots of functional facilities of different scales. The isodensity digital atlas was used to represent the topological relationship of elements in the space, and the isodensity hierarchical tree was used to represent the hierarchical relationship between elements. The specific map construction process is as follows: We first created an isodensity digital atlas based on the kernel density map generated by the POI, took the hot-spot area in which the four first-level facility hotspots were located as the root node (Figure 5), and then divided the hot spots into five levels by using the natural break clustering method. The class of hot spots was divided according to the critical 
value consistent with the classification of facility hot spots, and the hierarchical structural characteristics of various facility hot spots were analyzed from a horizontal perspective. The digital field-based hierarchical geo-information Tupu method applied in this study is shown in Figure 5.
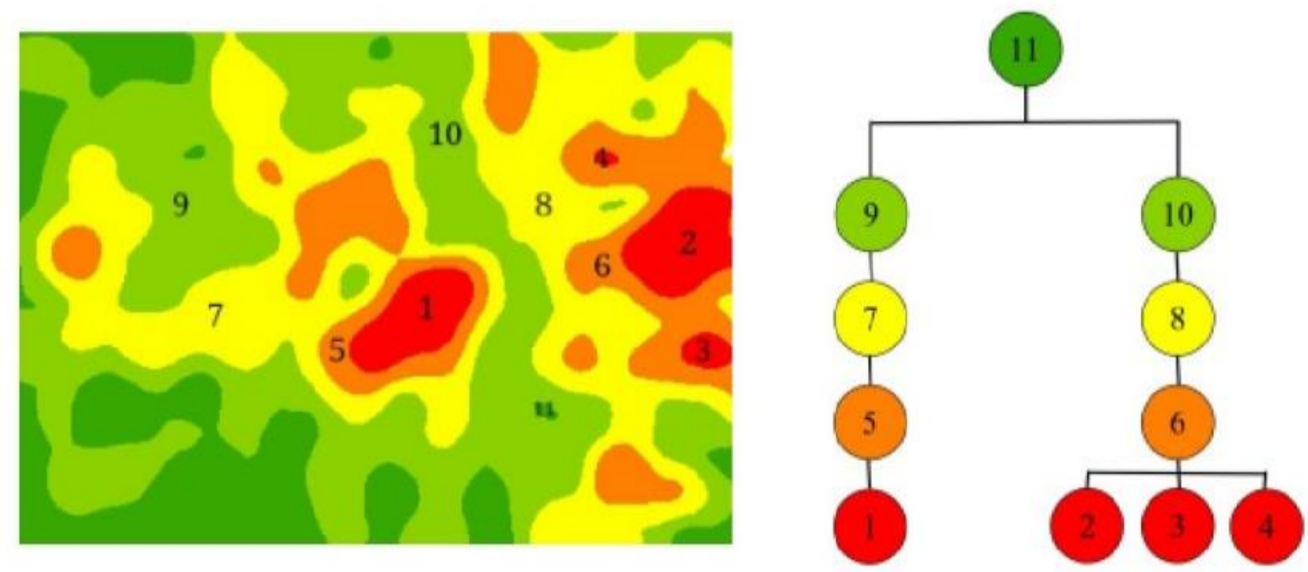

Figure 5. Digital field-based hierarchical geo-information Tupu.

\subsubsection{Functional Area use Intensity Analysis}

Tencent location data containing population distribution information were used to estimate the day and night population density of workdays and weekends corresponding to each grid area to reflect the use intensity of functional areas and their time differences. The distribution of urban functional areas was then characterized from a dynamic perspective. The use intensity of functional area refers to the degree of utilization of the area. The time difference of the use intensity of a functional area is the difference in activity in the points of interest on workdays, weekends, daytime, and nighttime. Here, we calculated the average population positioning times that the POI can serve in each grid area and recorded the values obtained as the daytime and nighttime use intensities of functional area $S i$. For each grid area $i$, the use intensity $S i$ of a functional area during the day and night is

$$
\begin{aligned}
S_{i, \text { day }} & =\frac{N_{i, \text { day }}}{P_{i, \text { day }}} \\
S_{i, \text { night }} & =\frac{N_{i, \text { night }}}{P_{i, \text { night }}}
\end{aligned}
$$

where $N i$, day represents the day population positioning in grid $i, N i$, night represents the night population positioning in grid $i, P i$, day represents the number of active POIs in grid $i$ during the day, and $P i$, night represents the number of active POIs in grid $i$ at night. Then, we normalized it with a linear function and converted the original data to the range of $[0,1]$. The closer $S^{*}$ is to 1 , the higher is the use intensity of the functional area.

\section{Results and Discussion}

\subsection{Functional Area Recognition Analysis}

The three levels of single-function areas, mixed-function areas, and no-data areas were visualized with maps by using ArcGIS. The distributions of single and mixed-function areas in the four districts of Jinan City Center are shown in Figure 6.

The figure shows single-function areas in red, mixed-function areas in blue, and nodata areas in gray. The crossovers between single- and mixed-function areas are mainly distributed at the centers of Jinan's four districts and concentrated in the northern part of Shizhong District, the eastern part of Luoyin District, the southern part of Tianqiao District, and the northern part of Lixia District (Figure 6). No-data areas are distributed at the 
peripheries of these four districts. The numbers of units in the three functional areas were counted, and the highest proportion of units was found in no-data areas (2272 units, 48.9\% of the total number of units). These units are mostly distributed across cultivated land, lakes, and woodlands. Mixed-function areas account for 735 units, representing only 15.8\% of the total number of units. Single-function areas account for 1643 units, representing $35.3 \%$ of the total number of units; these units are concentrated in the center of each study area.

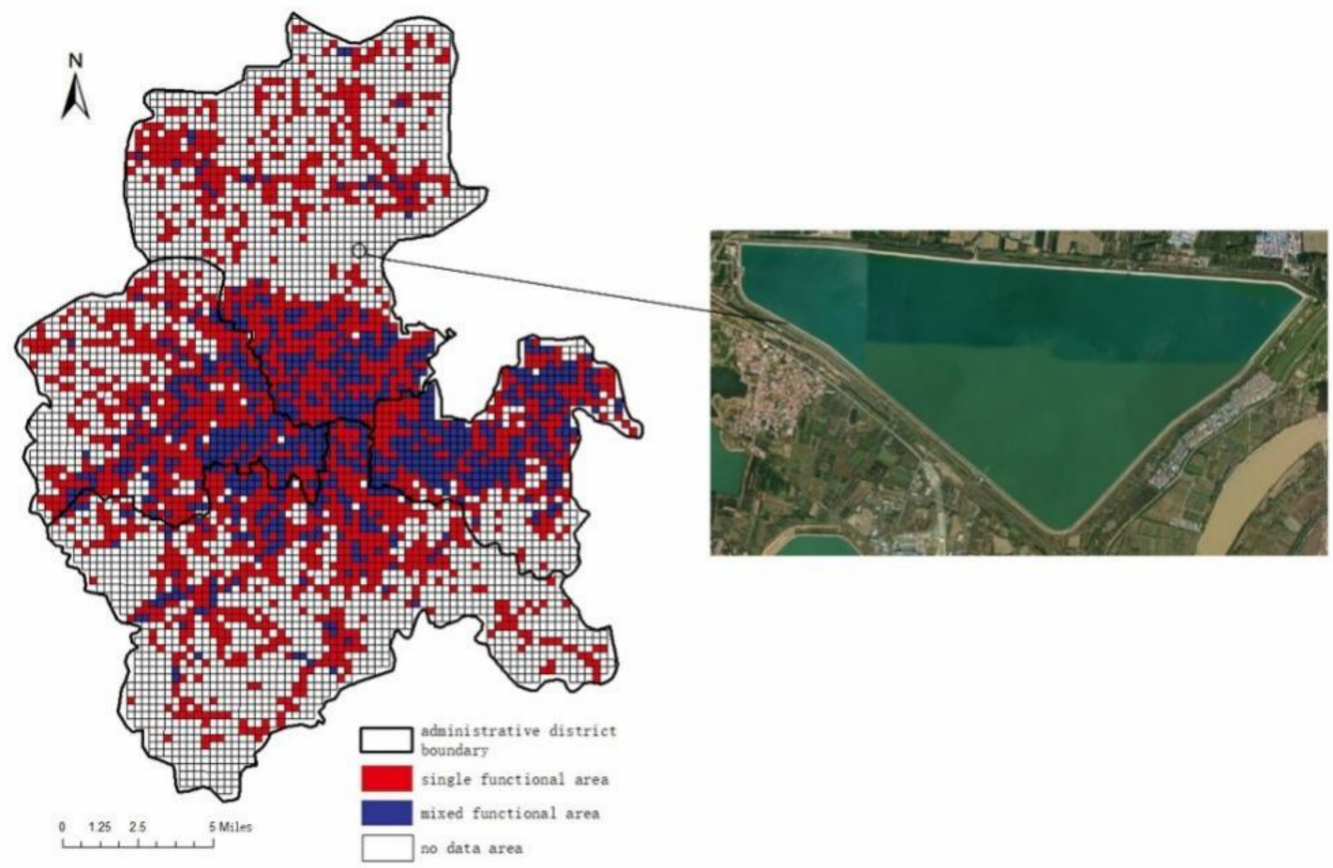

Figure 6. Distributions of the single-function areas, mixed-function areas, and no-data areas in the four districts of Jinan City.

In this study, single-function areas were divided into six categories-namely, residential land, public management and service facilities land, business facilities land, industrial land, road and transport facilities land, and green space and square land. Figure 7 shows the distribution of single-function areas in the four districts of Jinan City Center. Industrial land is distributed in Tianqiao District, mainly in Qilu Science and Technology City and Dingzhuangju Industrial Park. Residential land is concentrated in the southern part of Tianqiao District, the eastern part of Huaiyin District, and the northeastern part of Shizhong District. Moreover, in Lixia District, expansion toward the east, mainly in the vicinity of Dinghao Square, may be observed. Land used for business facilities is less concentrated and more evenly distributed in the main urban areas of the study area; the Jiguang Expressway in Tianqiao District, Jingshi Road in Huaiyin District, Second Ring Road South in Shizhong District, and Aoti Middle Road in Lixia District serve as the boundaries of spread to the surrounding areas. Roads and transport facilities show multicentric development trends in the four districts and are distributed in the east in Huaiyin District, Shizhong District, and Lixia District; these facilities are more scattered in Tianqiao District. Sites used for public management and service facilities are also widely distributed in the four districts, with the highest density found in the southern part of the Jingguang Expressway. Green space and square lands are highly concentrated and continuously distributed in Tianqiao District, Lixia District, and Shizhong District, particularly at Daming Lake, near Baotu, in scenic areas, or near square parks. 


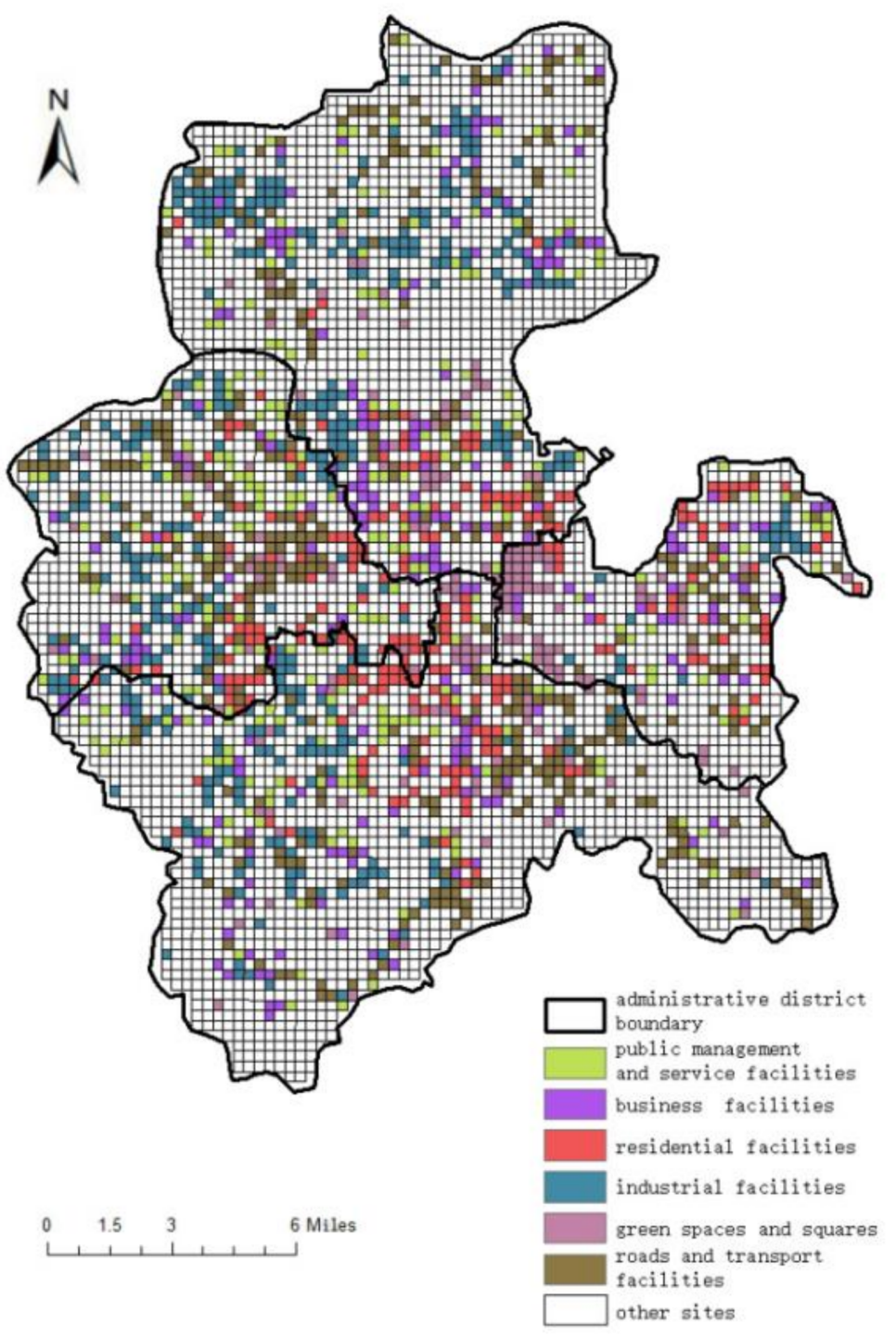

Figure 7. Single-function area zoning map.

A mixed-function area is a unit in which the proportions of all POI categories are less than $50 \%$. In this study, the three types of POIs with the highest proportions were selected on the basis of the nature of the functional area of the unit. After mixing the three POI types, 23 mixed-function areas are obtained. For example, a mixed unit of industrial land, residential land, and road and transport services land is referred to as industrial housing and expressed as ITR. A total of 22 mixed-land use types are found in the four districts of Jinan.

The mixed-function areas are mainly concentrated in the central areas of the four districts-namely, in the southern part of Tianqiao District, the southeastern part of Huaiyin District, Shizhong District, and the northern part of Lixia District. The distribution results are reflected in Figure 8. In Tianqiao District, most of the mixed-function areas are categorized as IBTs (industrial, business, and road and transport facilities). In Huaiyin District and Shizhong District, most areas are labeled IPB (industrial, public management and service, and business facilities). Lixia District has more units of IGB and PBT areas than other districts; as a result, business facilities, public management and service facilities, and industrial facilities are more widely distributed across this district than in other districts. 


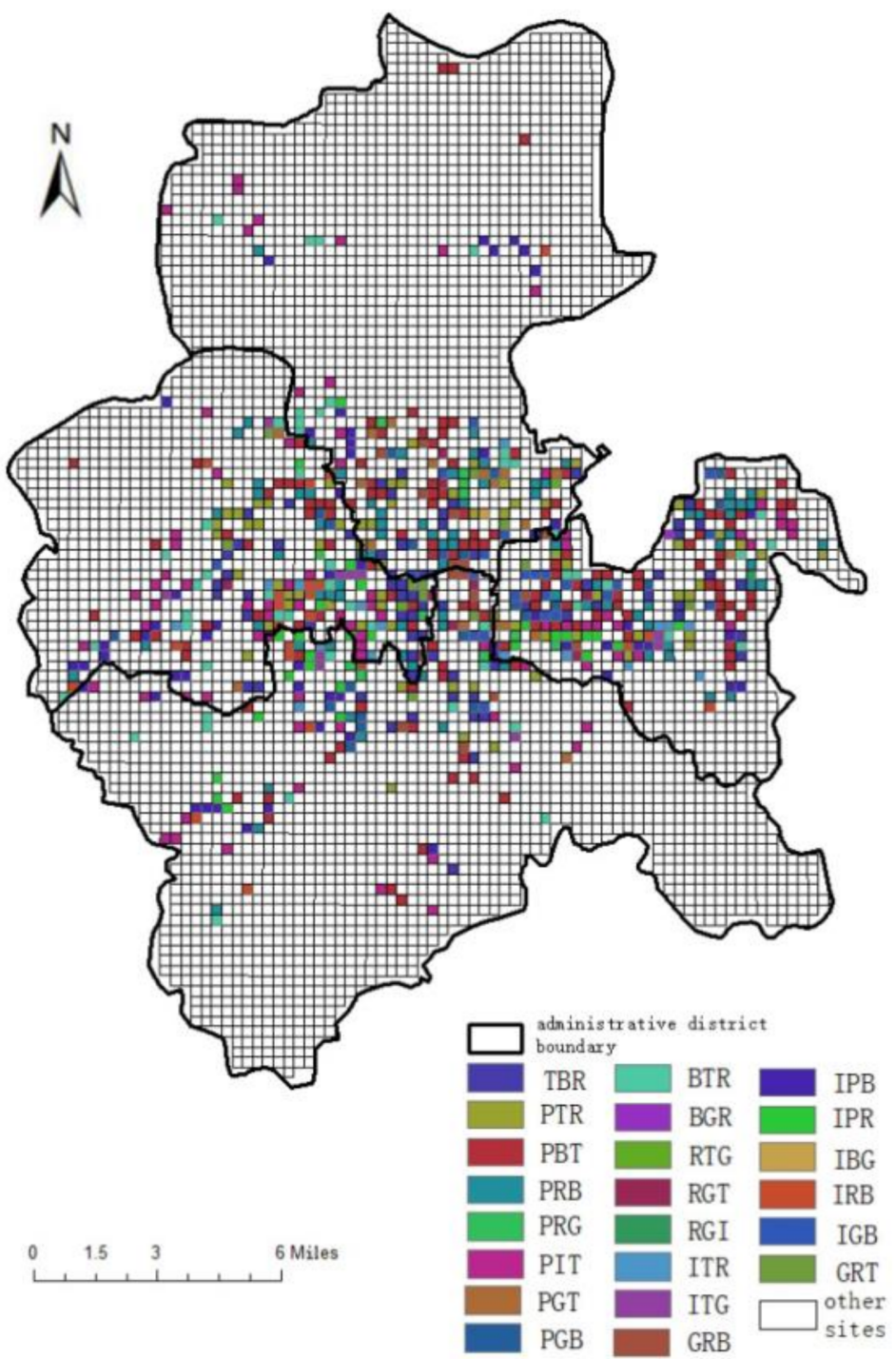

Figure 8. Zoning map of mixed-function areas.

\subsection{Hot-Spot Detection Analysis}

The spatial distributions and structural features of POI hot spots are presented using the generalized symmetric structure spectrum and digital field-based hierarchical geoinformation Tupu defined from a geographic perspective. The hot-spot detection results for public management and service facilities, residential land, and industrial land are shown in Figure 9. In this figure, the distribution hotspots of these three types of functional facilities form an axial-symmetrical structure. In addition, public management and service facilities and residential land hotspots present a synthetic symmetrical structural distribution.

However, only one large-scale hot spot for public management and service facilities could be observed in the western region of the research area; hot spots of four levels and below show a synthetic symmetrical structure. In terms of digital field hierarchy, five-level hot spots in the east, numbered 5, show an independent hierarchical structure at different scales, thereby indicating that this level forms the only hot spot in the region. In addition, the four other large hot spots are distributed in the form of a double nucleus, with fivelevel hot spots mainly distributed at the intersection of Jingshi Road and Nanxinzhuang West Road at Qilu Normal College and Dinghao Square. For residential facilities, the smallest hot-spot levels are distributed around the central region and show an overall symmetrical structural trend. Digital field-based hierarchical geo-information Tupu shows 
only two large hot spots among the distributed residential facilities in the four districts; these hot spots manifest relatively independent single-core characteristics and tend to extend eastward, mainly in the central regions of the districts. The hot-spot detection results for industrial facilities show a small number of hot spots at all levels, and the distributions of two- and four-level hot spots are axially symmetric. Only one large hot spot with an obvious single-nucleus distribution structure could be observed at the eastern region of Boardwalk Plaza.

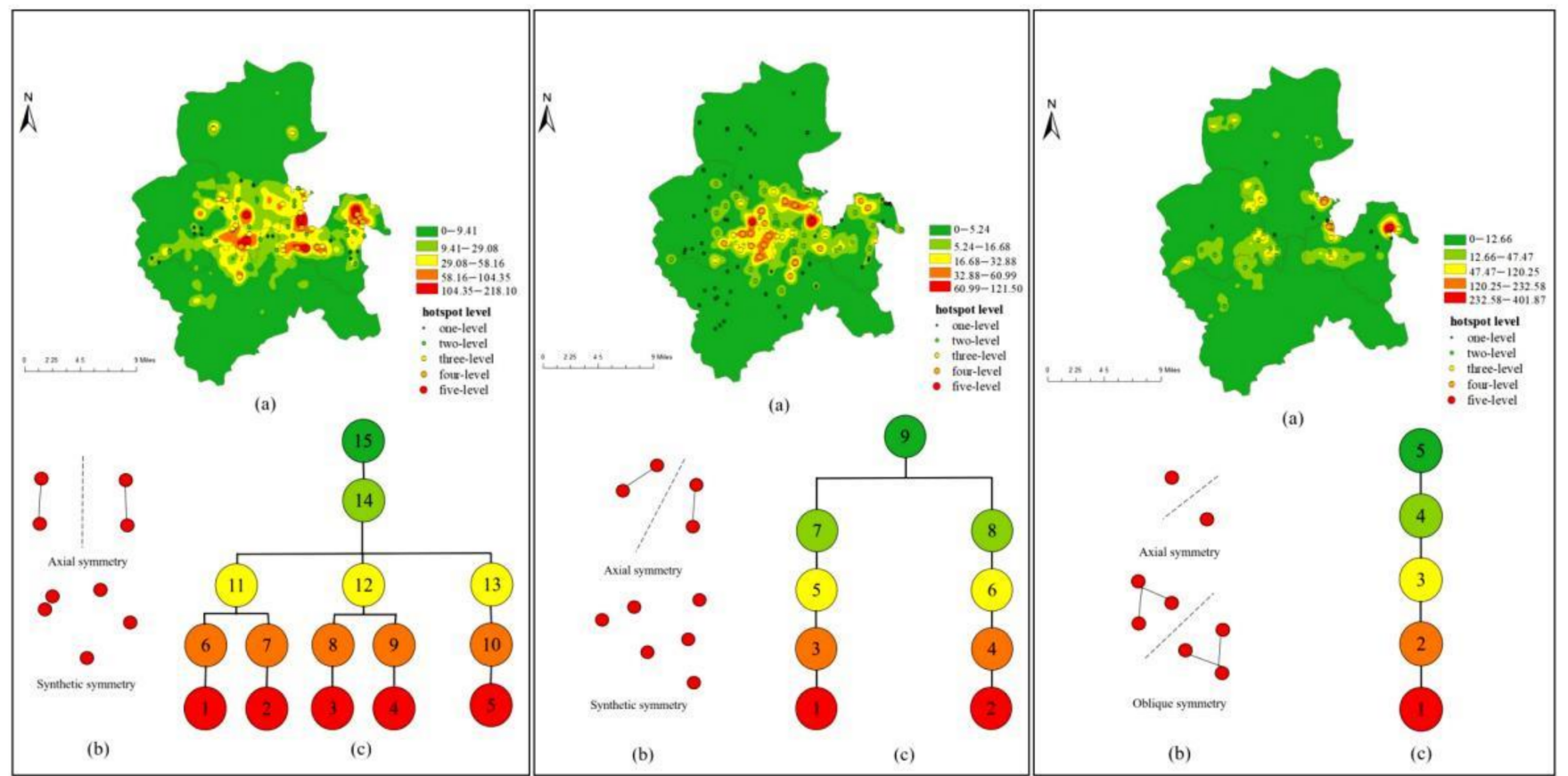

(A)

(B)

(C)

Figure 9. Hot-spot detection results of public management and service facilities, residential land, and industrial land: (A) public management and service facilities hot-spot detection results; (B) residential land hot-spot detection results; (C) industrial land hot-spot detection results. In the images, (a) is the isodensity digital atlas of the functional facility, (b) is the generalized symmetric structure spectrum of the functional facility, and (c) is the isodensity hierarchical tree of the functional facility.

The hot-spot detection results for roads and transport facilities reveal six five-level hot spots in the four districts, as well as an obvious multinuclear hot spot group structure (Figure 10). Among these six five-level hot spots, three show rotational-symmetrical distributions, and the remaining hot spots mainly show overall symmetrical structures. The digital field-based hierarchical geo-information Tupu results show the discrete and aggregated features of the hot-spot distribution. A total of six large road and transport facility hot spots (i.e., five-level hot spots of road and transport facility) are observed, and all six areas have independent hierarchies at different scale levels; these findings indicate that these five levels form the only hot spots in the corresponding regions. The number of secondary hot spots is relatively small, and the five levels numbered 1 and 2 are aggregated at the fourth level through node 13, thereby indicating that these five levels form the only hot spots around the region (Figure 10B). The five levels numbered 3, 4, and 5 are aggregated at the fourth level through node 14, indicating higher concentrations of roads and transport facilities in regions with greater numbers of hot spots of lower levels. Gathering areas are mainly located in the Lashan Overpass, Yanshan Overpass, and Qilu Software Park areas. The distribution structures of green space and square land facilities show four-level hot spots mainly distributed in an axial-symmetrical pattern and two-level hot spots distributed in an overall symmetrical pattern. Among the four central districts 
studied in this work, green space and square land facilities exhibit the fewest hot spots. Only one independent small-scale single-core gathering area could be observed, and this area is mainly distributed around the Baotu Spring scenic area.

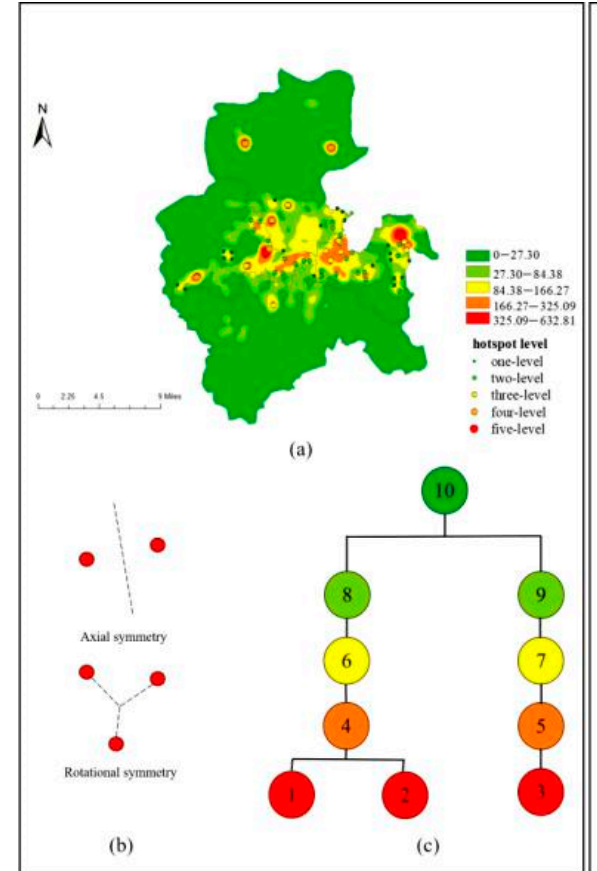

(A)

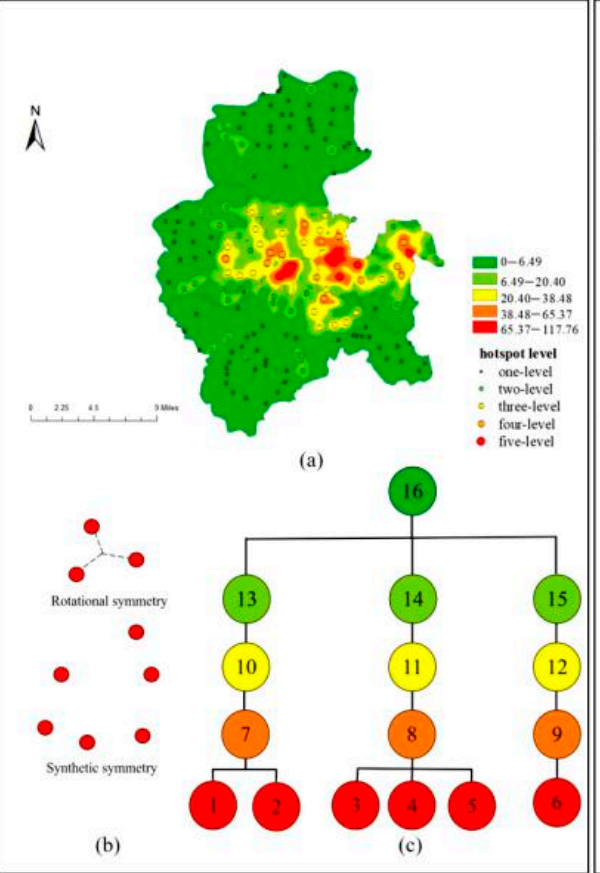

(B)

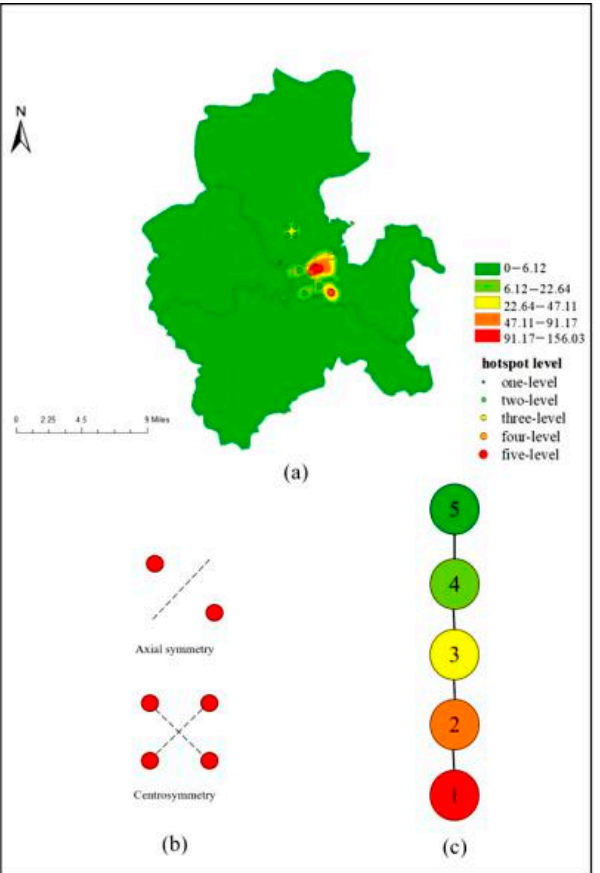

(C)

Figure 10. Hot-spot detection results of business facilities, road and transport facilities, and green spaces and square land: (A) business facilities hot-spot detection results; (B) road and transport facilities hot-spot detection results; (C) green spaces and square land hot-spot detection results. In the images, (a) is the isodensity digital atlas of the functional facility, (b) is the generalized symmetric structure spectrum of the functional facility, and (c) is the isodensity hierarchical tree of the functional facility.

Overall, business facilities, public management and service facilities, road and transport facilities, and residential land show the distribution characteristics of contiguous clusters, thereby reflecting the spatial structure of the clustering distribution of these facilities in the four districts of Jinan City Center. Industrial facilities and green space and square land facilities show multi-pole nuclear cluster-like distribution patterns; each of these types of facilities is found in the central city area. Various types of functional facilities are distributed according to the available geographical resources. Overall, compared with those in other regions, business facilities, public management and service facilities, road and transport facilities, and residential land are more densely distributed in the southern part of Tianqiao District, the eastern part of Huaiyin District, Shizhong District, and the northern part of Lixia District, where most of the busiest areas of Jinan are located. This finding demonstrates the considerable spatial overlap of various functional facilities in the four central districts of Jinan.

\subsection{Validation of Functional Area Recognition Results}

The functional area distribution map obtained from the experiment was compared to the remote sensing images obtained from USGS National Map Viewer (http:/ / viewer. nationalmap.gov/viewer/, accessed on 15 April 2019) to test the accuracy of the functional area recognition results, and four typical areas were used as examples for validation analysis. The identification results are shown in Table 3. 
Table 3. Comparison of the functional area identification results.

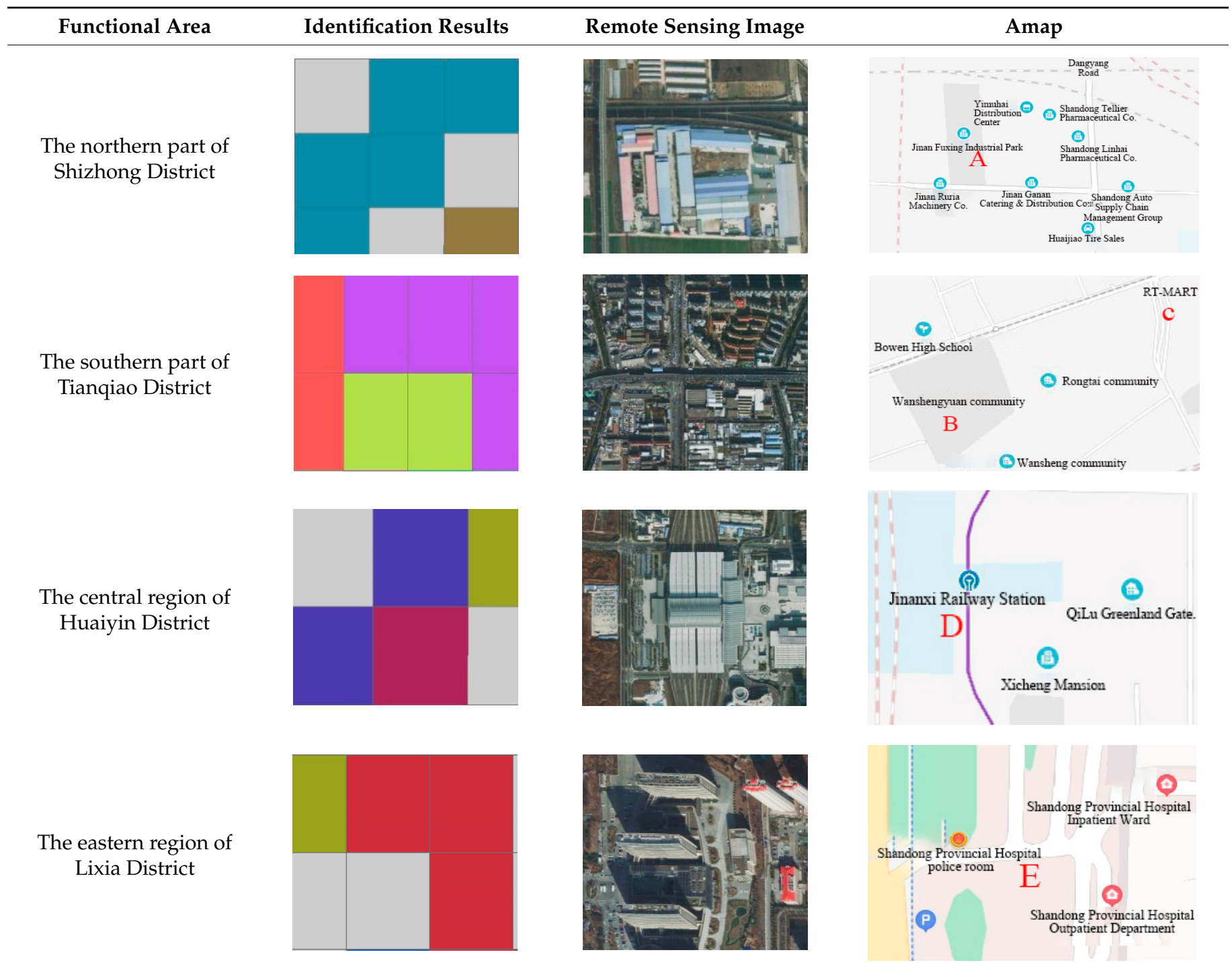

(1) The northern part of Shizhong District - in this study, area A is identified as industrial land, including companies and enterprises. Compared with the Amap and a remote sensing image, area A includes various companies and enterprises, such as the Jinan Fuxing Industrial Park and Shandong Linhai Pharmaceutical Company.

(2) The southern part of Tianqiao District-we selected two zones, that is, B and C, in the southern region of Tianqiao District. According to the distribution of the functional areas explored in this study, area B is identified as residential land, including residential areas, and area $C$ is identified as business facilities land, including supermarkets and banks. Compared with the Amap and a remote sensing image, area B is located in the Wanshengyuan area, and area $C$ is located near an RT-Mart supermarket.

(3) The central region of Huaiyin District - we selected central area D of Huaiyin District. In this study, area D is identified as a mixed-function area, including roads and transport facilities, business facilities, and residential land. According to the Amap and a remote sensing image, area D includes the Jinan West Station, Xicheng Tower, and Qilu Gate, which are indicated as green land in the residential area. As the area has clear mixed-function characteristics, the identification results could be considered accurate. 
(4) The eastern region of Lixia District-we selected region E, located in the eastern part of Lixia District. From the distribution of functional areas explored in this study, area $\mathrm{E}$ is identified as a mixed-function area for public management and service facilities, business facilities, and roads and transport facilities. Compared with the Amap and a remote sensing image, area E shows evident mixed-function characteristics, with the main facilities including the Jinan City Postal Administration, Shandong Provincial Hospital East Hospital, and the major Aoti Middle Road.

Considering the verification results described above, the identification results could be considered to be accurate.

\subsection{Analysis Results of Use Intensity of Functional Area}

We superimposed and analyzed the results of functional area identification with the $1 \mathrm{~km} \times 1 \mathrm{~km}$ grid of Tencent data and then statistically analyzed and selected the functional facilities with the largest proportions in the grid to obtain the temporal and spatial characteristics of the use intensity of various functional facilities.

In terms of spatial distribution, in the daytime, the use intensity of functional areas in the central area is much higher than that in the surrounding areas, and high-use intensity areas are formed in business districts, such as the World Trade Center. Figure 11 shows the results of the spatial distribution of the use intensity of various functional areas. Areas with low use intensity are distributed at the periphery of the study area, while areas with higher use intensity are mainly distributed within the inner regions of the city. Regardless of whether the day is a weekday or part of the weekend, the area of high use intensity during the day is much larger than that at night and mainly concentrated at the junction of the four districts. This finding may be explained by a large number of tourist attractions in this area, including Daming Lake Park, Qianfoshan Scenic Area, and Bao Tuquan Park, which have strong population absorption capacities. Compared with that during workdays, the use intensity of functional areas during weekends is significantly increased and mainly located in functional areas related to business facilities. This finding confirms that, compared with that of the five other types of functional facilities, the development of business facilities in Jinan City is at a higher level. The central and northern parts of the four districts show weak performance in the use intensity of functional areas. This finding is mainly due to the fact that fewer functional areas and large areas of land to be developed are available in these areas. In fact, in 2021, the Jinan Municipal Government proposed the building of a new and old kinetic energy conversion starting area in these locations to drive the quality of regional development and promote the coordinated development of the four districts.

The time difference of the use intensity of various functional facilities was further analyzed. Figure 12 presents the use intensity values of functional areas during the daytime and nighttime of workdays and weekends. The use intensity of the six types of functional facilities fluctuates greatly at 12:00 and 22:00 and is minimal at 4:00. During this time period, various functional facilities are in rest mode. Regardless of whether the day is a workday or part of the weekend, in addition to residential facilities, green space and square land facilities show the highest use intensity, thereby highlighting the tourist characteristics of Jinan City. The functional facilities with the lowest use intensity are roads and transport facilities. The maximum use intensity of functional facilities occurs at 12:00 in the daytime; however, in the weekend, the use intensity of these functional areas fluctuates greatly from 12:00 to 13:00 and generally shows a rapid decline, thereby indicating that the public has a completely different rhythmic life on workdays and weekends. In each time period studied, the difference in the use intensity of business facilities, public management and service facilities, and industrial facilities is relatively small, which indicates that the development of these three types of industries is relatively balanced. These findings collectively indicate that the urban spatial structure is related to the distribution density of service facilities but also to individuals' temporal and spatial activity patterns. 


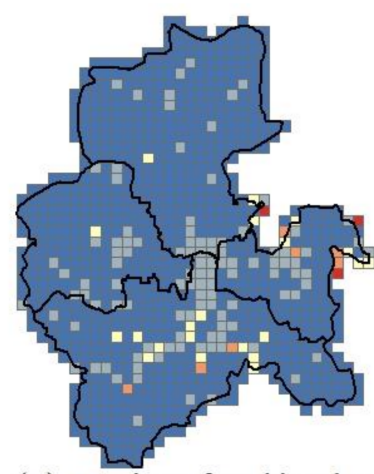

(a) Daytime of working day

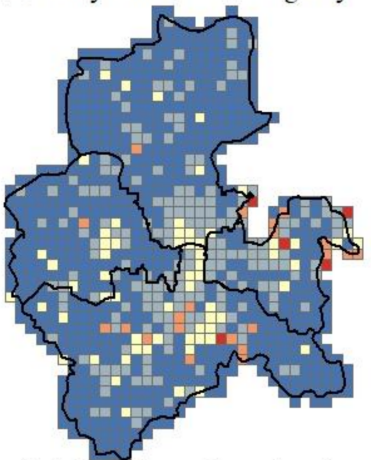

(c) Daytime of weekend

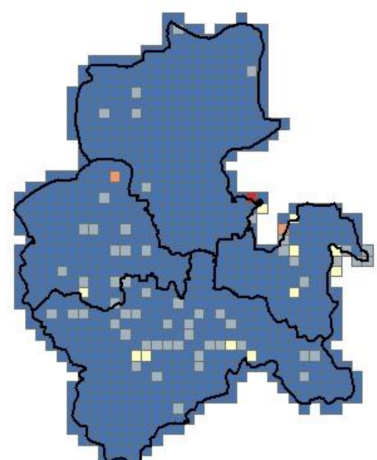

(b) Nighttime of working day

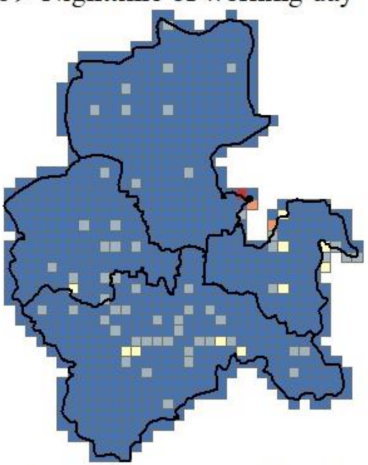

(d) Nighttime of weekend

$\stackrel{N}{N}$

Figure 11. Spatial distribution of use intensity in functional area (the intensity is the average value after normalization).

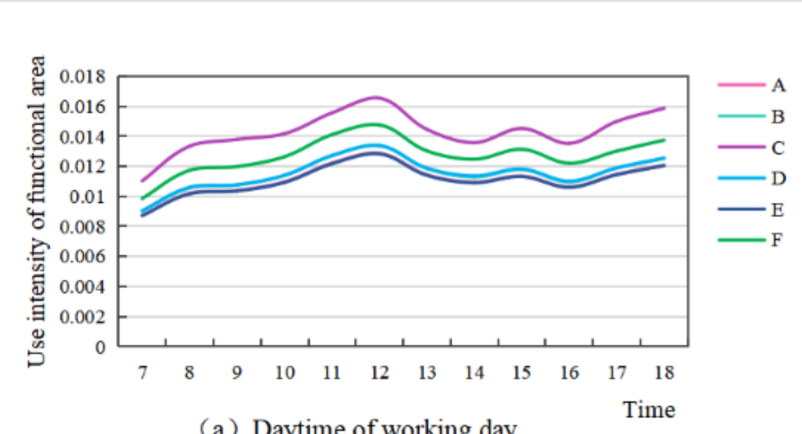

(a) Daytime of working day

(c) Daytime of weekend

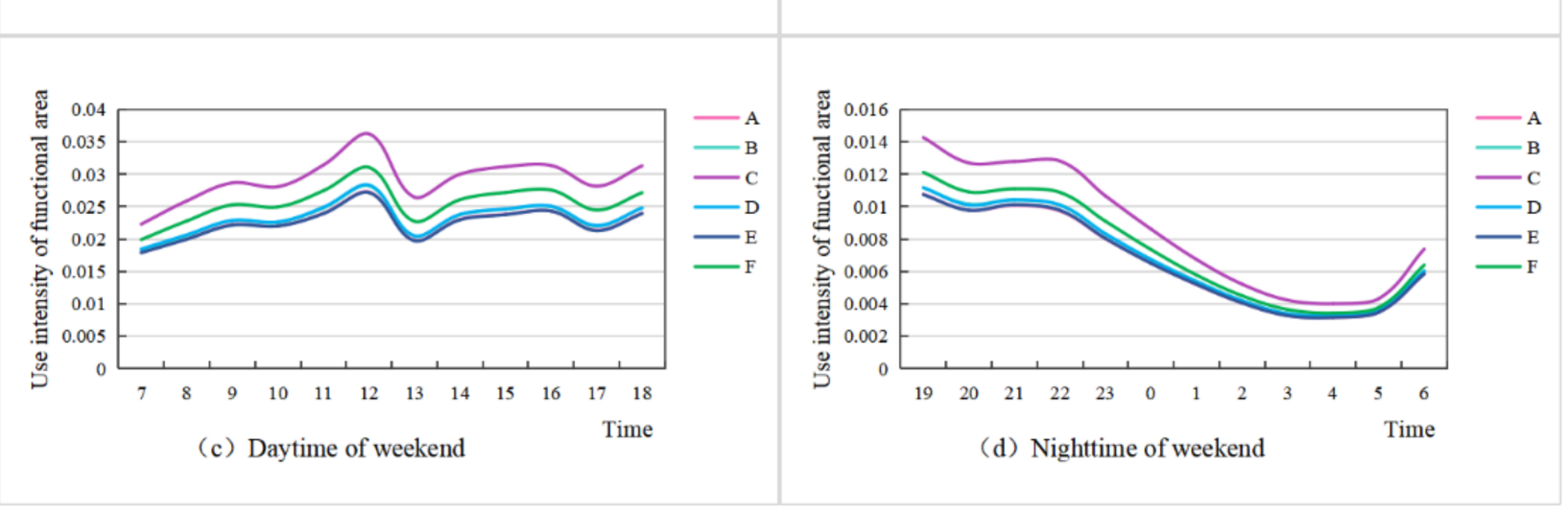

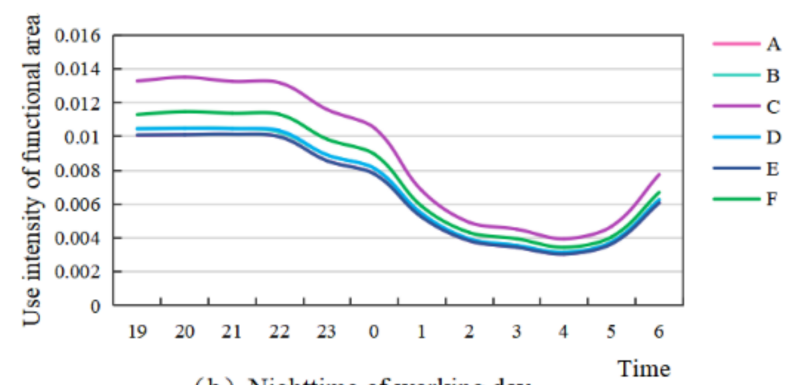

(b) Nighttime of working day

use intensity of functional area

$0.00-0.02$

$0.02-0.05$

$0.05-0.12$

$0.12-0.31$

$0.31-0.76$

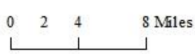

Figure 12. Use intensity of the different functional facilities in each period: A, business facilities; B, public management and service facilities; $C$, residential facilities; D, industrial facilities; E, roads and transport facilities; $F$, green spaces and square facilities. 


\section{Conclusions}

This paper proposed a GIS-based field model for hot-spot extraction based on POI data and analyzed the use intensity of various functional areas by using Tencent location data. We also employed a generalized symmetric structure spectrum and digital field-based hierarchical geo-information Tupu to express the spatial distribution characteristics and hierarchical scale of various facility hot spots comprehensively. We then introduced a use intensity index to quantify differences in the use intensity of different functional areas between workdays and weekends and between daytime and nighttime. A refined study of these functional areas was realized from a dynamic perspective. The main findings of the study are as follows:

(1) Business facilities in Jinan are distributed in a scattered pattern without large areas of high density; green space and square land facilities are mainly distributed in Lixia District, Tianqiao District, and City Central District with high degrees of concentration; (2) the distribution of all types of functional areas presents the characteristics of "circular structures," which form a spatial pattern of "multi-center" group and "single/mixed" functional areas; (3) the central and northern parts of Tianqiao District and the western part of Huaiyin District have low degrees of mixing and use intensity. Regardless of whether the day is a workday or part of the weekend, aside from residential facilities, green space and square land facilities have the highest use intensity, thus highlighting the tourist characteristics of Jinan City.

The above findings highlight the imbalance of development between the eastern and western regions of Jinan, and the difficulty in solving the problems left over by industrialization in the northern region. The construction of the districts of Tianqiao and Huaiyin on the basis of adhering to the development direction of "expanding from east to west, extending from south to north" could be strengthened to solve this problem. For example, in 2021, the Jinan Municipal Government proposed the building of a starting area for the conversion of new and old kinetic energy in Tianqiao District in an effort to achieve the overall coordinated and balanced development of the region. The planning direction also verifies the accuracy of the results of this study. The results of the present research show that the distribution of road and transport facilities in the study area is relatively concentrated and that high-value hot spots are mostly distributed in the central area. However, existing studies have shown that the central area is the core area of traffic congestion and is generally characterized by poor traffic mobility [34,35]. The urban traffic mobility system determines the spatial development pattern of urban frameworks and functional facilities [36,37]. Therefore, the government should rationally design traffic routes and develop a comprehensive traffic mobility system based on the city's unique topography and economic development characteristics; such a system could relieve the traffic pressure in the central region while strengthening progress in the surrounding areas of the city. The construction of regional functional facilities could include urban subcenters and fringe city clusters so that the distribution of urban space facilities is better balanced. In addition, the government should make full use of the accessibility of traffic lines to link various urban functional facilities closely and expand new urban areas. The above measures can promote the balanced development of urban areas, rationalize the urban spatial structure and organizational layout, optimize the spatial layout of urban functional facilities, improve traffic congestion, and promote the sustainable and healthy development of the city.

In summary, this paper discovered a large potential development space in some areas of the research area coinciding with the current regional planning policy of Jinan. As such, this research has important reference value for urban area development and planning. However, because of limited data accuracy and richness, the research and data processing methods may still be improved. For example, the weight value of various facilities directly represents the accuracy of functional areas. In future work, we will develop methods based on natural language to process POI data to endow our functional area recognition and refinement research with greater objectivity and accuracy. 
Author Contributions: Conceptualization, Mingyang Yu; Data curation, Jingqi Li and Huimeng Wang; Formal analysis, Jingqi Li and Huimeng Wang; Investigation, Jingqi Li and Huimeng Wang; Methodology, Mingyang Yu and Jingqi Li; Project administration, Mingyang Yu and Huaqiao Xing; Resources, Mingyang Yu; Supervision, Mingyang Yu; Writing—original draft, Jingqi Li and Huimeng Wang; Writing - review and editing, Huimeng Wang, Huaqiao Xing and Yongqiang Lv. All authors have read and agreed to the published version of the manuscript.

Funding: This workwas = supported by the National Science Foundation of China (41801308, 51608309) and the Shandong Social Science Planning Project (14DGLJ06).

Data Availability Statement: POI data are available at https://lbs.amap.com/, accessed on 15 April 2019; Tencent location data are available at https:// heat.qq.com, accessed on 27 March 2019; the remote sensing images are available at http://viewer.nationalmap.gov/viewer/, accessed on 15 April 2019; Open Street Map (OSM) data are available at https: / www.openstreetmap.org/, accessed on 18 April 2019.

Acknowledgments: We acknowledge Zhang Liu for helping us collect and provide Tencent positioning data.

Conflicts of Interest: The authors declare no conflict of interest.

\section{References}

1. Kang, Y.; Wang, Y.; Xia, Z.; Chi, J.; Jiao, L.; Wei, Z. Identification and Classification of Wuhan Urban Districts Based on POI. J. Geomat. 2018, 43, 81-85.

2. Chi, J.; Jiao, L.; Dong, T.; Gu, Y.; Ma, Y. Quantitative Identification and Visualization of Urban Functional Area Based on POI Data. J. Geomat. 2016, 41, 68-73.

3. Crooks, A.; Pfoser, D.; Jenkins, A.; Croitoru, A.; Stefanidis, A.; Smith, D.; Lamprianidis, G. Crowdsourcing urban form and function. Int. J. Geogr. Inf. Sci. 2015, 29, 720-741. [CrossRef]

4. Wu, Q.; Zhang, L.; WU, Z. Identifying City Functional Areas Using Taxi Trajectory Data. J. Geomat. Sci. Technol. 2018, 35, 413-418.

5. Shan, X.; Xu, J.; Liu, Y.; Sui, X.; He, X. A Research on Spatial Distribution Pattern of Urban Catering Industry in Kunming Based on POI Data. J. Kunming Univ. Sci. Technol. 2019, 44, 115-120.

6. Mao, Y.; Zhong, Y. Spatial pattern and influencing factors of urban vitality in the middle reaches of the Yangtze River. World Reg. Stud. 2020, 29, 86-95.

7. Xue, B.; Xiao, X.; Li, J.; Xie, X. Analysis of Spatial Economic Structure of Northeast China Cities Based on Points of Interest Big Data. Sci. Geogr. Sin. 2020, 40, 691-700.

8. Gao, S.; Janowicz, K.; Couclelis, H. Extracting urban functional regions from points of interest and human activities on locationbased social networks. Trans. GIS 2017, 21, 446-467. [CrossRef]

9. Gil, E.; Ahn, Y.; Kwon, Y. Tourist Attraction and Points of Interest (POIs) Using Search Engine Data: Case of Seoul. Sustainability 2020, 12, 7060. [CrossRef]

10. Yao, K.; Yue, S. Study on Spatial Distribution of Modern Sweet Diet and its Impact Factors in China based on Big Data from Internet. J. Geo-Inf. Sci. 2020, 22, 1202-1215.

11. Gao, Y.; Yang, Q.; Liang, L.; Zhao, Y. Spatial Pattern and Influencing Factors of Retailing Industries in Xi'an Based on POI Data. Sci. Geogr. Sin. 2020, 40, 710-719.

12. Zhan, D.; Xie, C.; Zhang, W.; Ding, L.; Xu, J. Identifying Mixed Functions of Urban Public Service Facilities in Beijing by Cumulative Opportunity Accessibility Method. J. Geo-Inf. Sci. 2020, 22, 1320-1329.

13. Salas-Olmedo, M.H.; Moya-Gómez, B.; García-Palomares, J.C.; Gutiérrez, J. Tourists' digital footprint in cities: Comparing big data sources. Tour. Manag. 2017, 66, 13-25. [CrossRef]

14. Luo, S.; Liu, Y.; Gao, S.; Wang, P. Quantitative identification of urban functional areas based on spatial grid. Bull. Surv. Mapp. 2020, 214-217. [CrossRef]

15. Liu, Z.; Du, Y.; Yi, J.; Liang, F.; Ma, T.; Pei, T. Quantitative Association between Nighttime Lights and Geo-Tagged Human Activity Dynamics during Typhoon Mangkhut. Remote Sens. 2019, 11, 2091. [CrossRef]

16. Liu, Z.; Du, Y.; Yi, J.; Liang, F.; Ma, T.; Pei, T. Quantitative estimates of collective geo-tagged human activities in response to typhoon Hato using location-aware big data. Int. J. Digit. Earth 2020, 13, 1072-1092. [CrossRef]

17. Yang, Z.; Su, J.; Yang, H.; Zhao, Y. Exploring urban functional areas based on multi-source data: A case study of Beijing. Geogr. Res. 2021, 40, 477-494.

18. Yu, W.; Ai, T.; Liu, P.; He, Y. Network Kernel Density Estimation for the Analysis of Facility POI Hotspots. Acta Geod. Cartogr. Sin. 2015, 44, 1378 .

19. Duan, Y.; Liu, Y.; Liu, X.; Wang, H. Identification of Polycentric Urban Structure of Central Chongqing Using Points of Interest Big Data. J. Nat. Resour. 2018, 33, 788-800.

20. Zhang, H.; Zhou, X.; Tang, G.; Zhou, L.; Ye, X. Hotspot discovery and its spatial pattern analysis for catering service in cities based on field model in GIS. Geogr. Res. 2020, 39, 354-369. 
21. Zhang, Y.; Min, J.; Liu, C.; Li, Y. Hotspot Detection and Spatiotemporal Evolution of Catering Service Grade in Mountainous Cities from the Perspective of Geo-Information Tupu. ISPRS Int. J. Geo-Inf. 2021, 10, 287. [CrossRef]

22. Zhang, H.; Zhou, X.; Tang, G.; Ji, G.; Zhang, X.; Xiong, L. Inference method for cultural diffusion patterns using a field model. Trans. GIS 2020, 24, 1578-1601. [CrossRef]

23. Zhang, H.; Zhou, X.; Huang, Y. Analysis of Spatial Interaction between Different Food Cultures in South and North China: Practices from People's Daily Life. ISPRS Int. J. Geo-Inf. 2020, 9, 68. [CrossRef]

24. Jiang, S.; Zhang, H.; Wang, H.; Zhou, L.; Tang, G. Using Restaurant POI Data to Explore Regional Structure of Food Culture Based on Cuisine Preference. ISPRS Int. J. Geo-Inf. 2021, 10, 38. [CrossRef]

25. Chi, L.; Song, W.; Zhu, X. Spatial Data Analysis and Visualization of Urban POI. Geomat. Spat. Inf. Technol. 2020, 43, 109-113.

26. Zhao, J.; Li, H.; Deng, S.; Jiang, J. Identifying Urban Functional Regions Based on POI Data and Spatial Analysis of Main Transit Hubs. Geomat. Spat. Inf. Technol. 2019, 42, 38-42.

27. Li, Q.; Zheng, X.; Chao, Y. Research on function identification and distribution characteristics of Wuhan supported by big data. Sci. Surv. Mapp. 2020, 45, 119-125.

28. Zhang, J.; Shi, W.; Xiu, C. Urban Research Using Points of Interest Data in China. Sci. Geogr. Sin. 2021, 41, 140-148.

29. Zhao, W.; Li, Q.; Li, B. Extracting hierarchical landmarks from urban POI data. J. Remote Sens. 2011, 15, $973-988$.

30. Li, X. Recognition of Urban Polycentric Structure Based on Spatial Aggregation Characteristics of POI Elements: A Case of Zhengzhou City. Acta Sci. Nat. Univ. Pekin. 2020, 56, 692-702.

31. Yi, D.; Yang, J.; Liu, J.; Liu, Y.; Zhang, J. Quantitative Identification of Urban Functions with Fishers' Exact Test and POI Data Applied in Classifying Urban Districts: A Case Study within the Sixth Ring Road in Beijing. ISPRS Int. J. Geo-Inf. 2019, 8, 555. [CrossRef]

32. Hu, Y.; Han, Y. Identification of Urban Functional Areas Based on POI Data: A Case Study of the Guangzhou Economic and Technological Development Zone. Sustainability 2019, 11, 1385. [CrossRef]

33. Chen, S.; Yue, T.; Li, H. Studies on Geo-Informatic Tupu and its application. Geogr. Res. 2000, 337-343.

34. Li, H. Brief Analysis of Traffic Congestion in Jinan-Take Tokyo for Reference. Heilongjiang Jiaotong Keji 2020, 43, 197-200.

35. Han, L. Discussion on Current Traffic Situation and Reconstruction Measures. Urban. Archit. 2020, $17,35-37$.

36. Tiboni, M.; Rossetti, S.; Vetturi, D.; Torrisi, V.; Botticini, F.; Schaefer, M.D. Urban Policies and Planning Approaches for a Safer and Climate Friendlier Mobility in Cities: Strategies, Initiatives and Some Analysis. Sustainability 2021, 13, 1778. [CrossRef]

37. Carpentieri, G.; Guida, C.; Chorus, P. Land-Use and Transport integration polices and real estate values. The development of a GIS methodology and the application to Naples (Italy). TeMA-J. Land Use Mobil. Environ. 2019, 12, 313-330. [CrossRef] 